\title{
ENTRE O LIBERALISMO E O REPUBLICANISMO: HABERMAS E A DEMOCRACIA DELIBERATIVA
}

\author{
Juliano Cordeiro da Costa Oliveira ${ }^{1}$
}

\begin{abstract}
Resumo:
$\mathrm{O}$ artigo enfatiza o conceito de democracia deliberativa proposto por Jürgen Habermas. Este conserva os momentos positivos do liberalismo e do republicanismo, ao mesmo tempo em que supera aquilo que considera negativo tanto de um como de outro. É a partir da síntese entre liberalismo e republicanismo que Habermas articulará seu conceito de democracia deliberativa, haja vista que ambas as tradições, segundo Habermas, são insuficientes para pensarmos as demandas políticas contemporâneas. Na Teoria do Agir Comunicativo, de 1981, Habermas ainda não havia refletido questões de sua filosofia política, como liberdade, Estado democrático de direito, esfera pública, movimentos sociais, soberania popular, direitos humanos, entre outras. Apenas em Direito e Democracia, obra de 1992, que Habermas formulará a ideia de uma democracia deliberativa, conceito este que servirá de referência para todas as recentes reflexões políticas habermasianas. Primeiramente, explicitaremos a análise de Habermas acerca do liberalismo e do republicanismo, mostrando como ele articula a síntese entre ambas as tradições. Em seguida, destacaremos propriamente o conceito de democracia deliberativa. Finalmente, debateremos a complexa relação entre esfera pública e parlamento, destacando a importância dos movimentos sociais na renovação política. O pensamento pós-metafísico habermasiano tornou possível, como veremos, a articulação do conceito de democracia deliberativa, mediado por uma crítica tanto ao liberalismo como ao republicanismo que, em Habermas, ganha novos aspectos, através da tentativa de síntese entre ambas as tradições. A reflexão política, em Habermas, resulta também de um desafio de superar um suposto "déficit democrático" existente no interior da Teoria Crítica, exceção feita aos trabalhos de Franz Neumann e Otto Kirchheimer. Habermas é capaz disso?
\end{abstract}

Palavras-Chave: Habermas. Liberalismo. Republicanismo. Democracia Deliberativa.

\section{BETWEEN LIBERALISM AND REPUBLICANISM: HABERMAS AND DELIBERATIVE DEMOCRACY}

\begin{abstract}
:
The article emphasizes the concept of deliberative democracy proposed by Jürgen Habermas. It preserves the positive moments of liberalism and republicanism at the same time that it overcomes what is considered negative either of one or the other. It is starting from the synthesis between liberalism and republicanism that Habermas will articulate his concept of deliberative democracy, considering that both traditions, according to Habermas, are insufficient for thinking about contemporary political demands. In his Theory of Communicative Action, 1981, Habermas had not yet reflected questions of his political philosophy, such as freedom, democratic state of law, public sphere, social movements, popular sovereignty and human rights, among others. It was only in Between Facts and Norms, written in 1992, that Habermas formulated the idea of a deliberative democracy, concept henceforth used as a reference for all his recent political reflections. Firstly, we shall explain Habermas's analysis of liberalism and republicanism, showing how he articulates the synthesis between both traditions. Next, we will properly emphasize the concept of deliberative democracy. Finally, we shall discuss the complex relationship between the public sphere and the parliament, highlighting the importance of social movements in political renewal. Habermas's post-metaphysical thought has enabled the articulation of the deliberative democracy concept, mediated by a critique of both liberalism and republicanism, which, in Habermas, gains new aspects through an attempt to synthesize both traditions. The political reflection in Habermas
\end{abstract}

\footnotetext{
${ }^{1}$ Doutor em Filosofia pela Universidade Federal do Ceará (UFC), com Doutorado Sanduíche pela Ludwig-Maximilian-Universität (LMU), em Munique, Alemanha. Email: julianocordeiro81@gmail.com.
} 
also results from a challenge to overcome a supposed "democratic deficit" within Critical Theory, except for the works of Franz Neumann and Otto Kirchheimer. Is Habermas really able to do that?

Keywords: Habermas. Liberalism. Republicanism. Deliberate Democracy.

\section{Introdução}

Reconstruiremos, neste artigo, aquilo que podemos chamar de uma Filosofia Política de Jürgen Habermas, por meio do conceito de democracia deliberativa. $\mathrm{O}$ pensamento pós-metafísico de Habermas tornou possível, na filosofia política, a articulação do conceito de democracia deliberativa, mediado por uma crítica tanto ao liberalismo como ao republicanismo que, em Habermas, ganha novos aspectos, através da tentativa de síntese entre ambas as tradições.

O direito e a democracia tornaram-se, por exemplo, no pensamento habermasiano, temas centrais, principalmente a partir de Direito e Democracia, obra de 1992. Na Teoria do Agir Comunicativo, de 1981, Habermas ainda não havia refletido questões de sua filosofia política, como liberdade, Estado democrático de direito, soberania popular, direitos humanos, entre outras. Além disso, em Direito $e$ Democracia, Habermas retoma algumas discussões políticas anteriores à Teoria do Agir Comunicativo, tal qual o problema da esfera pública, dos movimentos sociais e sua relação com o poder.

Com Direito e Democracia, Habermas enfatiza que pretende mostrar "que a teoria do agir comunicativo, ao contrário do que se afirma muitas vezes, não é cega para a realidade das instituições" (HABERMAS, 1997a, p.11). A reflexão política, em Habermas, resulta também de um desafio de superar um suposto "déficit democrático" existente no interior da Teoria Crítica (SILVA, 2008), exceção feita aos trabalhos de Franz Neumann e Otto Kirchheimer (REPA, 2008).

\section{A Compreensão Habermasiana do Modelo Liberal de Política.}

Habermas, primeiramente, expõe as concepções liberais e republicanas de política, para chegar, partindo do que há de positivo nos dois ideais, a um terceiro modelo novo de política: a deliberativa. Ele argumenta que, na concepção liberal de política, o Estado é um aparato da administração pública, estruturado segundo leis de mercado. A política, sob essa perspectiva, tem a função de congregar e impor interesses

\begin{tabular}{|l|l|l|l|l|}
\hline Q Rovista Dialectus & Ano 4 & n. 11 & Agosto - Dezembro 2017 & p. 280-296 \\
\hline
\end{tabular}


sociais, mediante um aparato estatal já especializado no uso administrativo do poder político.

\begin{abstract}
Na perspectiva liberal, o processo democrático se realiza exclusivamente na forma de compromissos de interesses. $E$ as regras da formação do compromisso, que devem assegurar a equidade dos resultados, e que passam pelo direito igual e geral ao voto, pela composição representativa das corporações parlamentares, pelo modo de decisão, pela ordem dos negócios, etc., são fundamentadas, em última instância, nos direitos fundamentais liberais (HABERMAS, 1997b, p.19) ${ }^{2}$.
\end{abstract}

A política liberal é determinada pela concorrência entre aqueles que agem estrategicamente, almejando a manutenção ou a conquista de posições de poder. O êxito nesta concepção de política é medido de acordo com a concorrência dos cidadãos em relação a pessoas e programas, o que se quantifica a partir dos números de votos. Numa palavra, as eleições têm a mesma estrutura que os atos eletivos de participantes do mercado voltados à conquista de êxito, uma vez que os partidos políticos lutam numa perspectiva que se orienta pela busca do sucesso. Os eleitores licenciam, através dos partidos políticos, o acesso a posições de poder, por meio de uma democracia indireta.

O modelo de política liberal não consiste na autodeterminação democrática das pessoas que deliberam, tal qual no formato republicano de política. No liberalismo, a ênfase é dada na liberdade enquanto autonomia individual. Nas palavras de Locke, por exemplo, “(...) cada homem tem uma propriedade em sua própria pessoa; a esta ninguém tem qualquer direito senão ele mesmo" (LOCKE, 1978, p. 45). Nesse sentido, os direitos humanos possuem uma maior relevância em relação ao ideal da soberania popular, pois há o destaque da autonomia privada em contraposição à pública.

Os liberais destacam a institucionalização jurídica de liberdades iguais, entendendo-as como direitos subjetivos. Para eles, os direitos humanos possuem um primado normativo em relação à democracia republicana. Na interpretação liberal, a formação democrática da vontade tem como principal função a legitimação do exercício do poder político, por meio de uma normatização constitucional.

\footnotetext{
2 "Nach liberaler Auffassung vollzieht sich der demokratische Prozeß ausschließlich in der Form von Interessenkompromissen. Die Regeln der Kompromißbildung, die über das allgemeine und gleiche Wahlrecht, über die representative Zusammensetzung der parlamentarischen Körperschaften, über den Entscheidungsmodus, die Geschäftsordung usw. die Faineß der Ergebnisse sichern sollen, werden letztlich aus liberalen Grundrechten begründet" (HABERMAS, 1992, p.359).

\begin{tabular}{|l|l|l|l|l|}
\hline Qevista Dialectus & Ano 4 & n. 11 & Agosto - Dezembro 2017 & p. $280-296$ \\
\hline
\end{tabular}
}


No liberalismo, os direitos são entendidos como garantias de determinadas liberdades subjetivas. Os direitos subjetivos definem liberdades de ação iguais para todos os indivíduos ou pessoas jurídicas, tidas como portadoras de direitos.

O liberalismo, na perspectiva habermasiana que remonta a Locke, conseguiu exorcizar, a partir do século XIX, o perigo das maiorias tirânicas, postulando, contra a soberania do povo, a procedência dos direitos humanos. A autonomia privada dos membros da sociedade seria garantida através dos direitos humanos (os direitos clássicos à "liberdade, à vida e à propriedade").

Não por acaso Locke afirma que cada homem tem uma propriedade em sua própria pessoa, uma vez que a mesma, através do trabalho, fundamenta também o indivíduo. "O trabalho que era meu, retirando-os do estado comum em que se encontravam fixou a minha propriedade sobre eles" (LOCKE, 1978, p.46). Em Locke, o homem tem o dever não só de preservar sua propriedade (a vida, a liberdade e os bens) contra os danos e ataques dos outros homens, mas também de julgar e castigar as infrações dessa lei.

Há, em Locke, e também na tradição liberal, uma perspectiva determinante que é a da obediência necessária às normas, pois as infrações cometidas contra a sociedade devem ser penalizadas, de acordo com o estabelecido em lei. Tudo isso constitui, para Locke, a sociedade política, porque ninguém pode isentar-se das leis que regem uma sociedade. Do contrário, o homem se encontraria ainda no estado de natureza, não podendo ser membro ou parte da sociedade civil. Segundo ele, a sociedade política não pode existir sem ter em si o poder de preservar a propriedade, de modo que um governo sem lei é inconcebível e incompatível com a sociedade dos homens.

Locke afirma que o poder absoluto também é limitado, restringindo-se aos seus objetivos pactuados pelos homens. Há, em Locke, o direito à resistência, caso o Estado descumpra o pacto social e desobedeça ao direito natural: os liberais destacam o perigo de uma tirania da maioria, postulando o primado dos direitos humanos que garantem as liberdades pré-políticas do indivíduo, opondo-se também à vontade soberana do legislador político.

Sobre os aspectos negativos da política liberal, Habermas explica que esta destaca unicamente uma política ligada ao aparelho do Estado, desprezando o conjunto de cidadãos capazes de agir. Tal centralismo político impede o potencial comunicativo

\begin{tabular}{|l|l|l|l|l|}
\hline Q Ponista Dialectus & Ano 4 & n. 11 & Agosto - Dezembro 2017 & p. 280-296 \\
\hline
\end{tabular}


dos cidadãos, pois seria o Estado unicamente o encarregado do fazer político. Todavia, Habermas considera positiva a questão da normatização jurídica e a ênfase nas liberdades individuais e nos direitos humanos, presentes no modelo liberal (aspectos estes da política liberal que Habermas se utilizará na elaboração do conceito de democracia deliberativa) que, em contrapartida, é deixado em segundo plano no modelo republicano de política, que veremos a seguir.

\section{A Compreensão Habermasiana do Modelo Republicano de Política.}

Acerca da visão republicana, Habermas demonstra que, ao contrário da liberal, a política é constitutiva do processo de coletivização social como um todo. O republicanismo defende princípios de participação e comunicação, que possibilitam a autodeterminação dos cidadãos. Concebe-se a política como forma de reflexão sobre um contexto de vida ético. Habermas destaca que ela constitui o medium em que os integrantes de comunidades solidárias, surgidas de forma natural, conscientizam-se de sua interdependência mútua. No republicanismo, a formação da vontade tem a função de constituir a sociedade enquanto uma coletividade política e de manter viva a cada eleição a lembrança desse ato fundador.

Deste modo, os cidadãos dão forma e prosseguimento às relações preexistentes de reconhecimento mútuo, transformando-as de forma voluntária e consciente em uma associação de juris-consortes livres e iguais. Os representantes de um humanismo republicano dão destaque ao valor próprio, não instrumentalizável, da auto-organização dos cidadãos, de modo que, aos olhos de uma comunidade naturalmente política, os direitos humanos só se tornam obrigatórios enquanto elementos de sua própria tradição, assumida conscientemente.

$\mathrm{Na}$ interpretação republicana, a formação democrática da vontade se realiza na forma de um auto-entendimento ético-político. Então, a liberdade se relaciona com a autonomia do povo soberano que se autodetermina. De acordo com a leitura habermasiana do republicanismo, há uma ênfase na autonomia pública em relação à privada, como também na soberania do povo em contraposição aos direitos humanos. A formação política da vontade constitui o medium através do qual a sociedade se entende como um todo estruturado politicamente. O republicanismo que remonta também a

\begin{tabular}{|l|l|l|l|l|}
\hline Gevista Dialectus & Ano 4 & n. 11 & Agosto - Dezembro 2017 & p. $280-296$ \\
\hline
\end{tabular}


Aristóteles sempre colocou a liberdade antiga (da comunidade), na frente da liberdade moderna (do indivíduo).

No Livro Primeiro da Política, Aristóteles (1253a2) destaca que o homem é naturalmente um animal político, destinado a viver em sociedade, à medida que a natureza compele todos os homens a se associarem. Para Aristóteles, o homem, tendo atingido sua perfeição, é o mais excelente de todos os animais; entretanto, é o pior quando vive isolado. Apenas o homem, para Aristóteles, entre todos os animais, tem o dom da palavra. Esta tem por finalidade compreender o que é útil ou prejudicial, e, por conseguinte, o que é justo ou injusto.

No Livro Segundo da Política, Aristóteles (1261a2) diz que de nada participar é impossível, porque a sociedade política é uma espécie de comunidade, uma vez que a cidade pertence em comum a todos os cidadãos. Aqui, o conceito de cidadania está diretamente relacionado à prática de deliberar, num mesmo solo, em torno das questões acerca da cidade. Chamamos cidade, diz Aristóteles (1275b8), no Terceiro Livro da Política, à multidão de cidadãos capaz de bastar a si mesma e de obter tudo que é necessário à sua existência. A cidade é a associação dos homens livres. A política, no sentido aristotélico, é considerada a mais elevada das ciências. Seu bem é a justiça, isto é, a utilidade geral.

Aristóteles foi o primeiro filósofo a distinguir a ética da política, porque a primeira diz respeito à ação voluntária e moral do indivíduo enquanto tal; já a segunda tem a ver com as vinculações do sujeito com a comunidade que delibera acerca das questões públicas. No republicanismo, a sociedade é por si mesma sociedade política societas civilis; pois, na prática de autodeterminação política, a comunidade toma consciência de si mesma, por meio da vontade coletiva dos sujeitos. Nesse sentido, o indivíduo, para os gregos, não possui o mesmo sentido dos modernos, pois, aqui, o indivíduo encontra-se, desde sempre, numa convivência com outros indivíduos: a vida em comum tem seu fundamento na virtude.

No modelo republicano, segundo a leitura habermasiana, há uma base social autônoma por parte dos cidadãos, que independe da administração pública e da mobilidade socioeconômica privada, impedindo a comunicação política de ser tragada pelo Estado e assimilada totalmente pelo mercado. A democracia, no sentido republicano, tem como fundamento a auto-organização política da sociedade.

\begin{tabular}{|l|l|l|l|l|}
\hline Q Rovista Dialeatus & Ano 4 & n. 11 & Agosto - Dezembro 2017 & p. $280-296$ \\
\hline
\end{tabular}


Disso resulta uma compreensão de política dirigida polemicamente contra o aparelho do Estado. Na interpretação republicana, o povo é o titular de uma soberania que não se deixa representar: o poder constituinte baseia-se na prática de autodeterminação das pessoas privadas, não de seus representantes.

Além de Aristóteles, Habermas cita Rousseau ${ }^{3}$, como um dos nomes fundamentais do republicanismo, para o entendimento da democracia deliberativa. De acordo com Rousseau, só a vontade geral pode dirigir as forças do Estado, tendo em vista o bem comum. No capítulo I, intitulado A soberania é inalienável, do Livro Segundo do Contrato Social, Rousseau afirma que o soberano é um ser coletivo, movido pela vontade geral. A soberania da vontade geral só pode ser representada por ela mesma. "A soberania é indivisível pela mesma razão por que é inalienável, pois a vontade ou é geral, ou não o é; ou é a do corpo do povo, ou somente de uma parte" (ROUSSEAU, 1978, p. 44). É nula, explica Rousseau, toda lei que o povo diretamente não ratificar.

Segundo ele, o povo, submetido às leis, deve ser o seu autor. Só àqueles que se associam cabe regulamentar as condições da sociedade. Por isso, não pode ser considerado livre um povo que possui representantes:

\begin{abstract}
Afirmo, pois, que a soberania, não sendo senão o exercício da vontade geral, jamais pode alienar-se, e que o soberano, que nada é senão um ser coletivo, só pode ser representado por si mesmo. O poder pode transmitir-se; não, porém, a vontade. (ROUSSEAU, 1978, p. 43-44).
\end{abstract}

Além disso, Rousseau enfatiza que cada povo pode ter um sistema particular de instituições. "Em uma palavra, além das máximas comuns a todos, cada povo reúne em si alguma coisa que o dirige de modo todo especial e torna sua legislação adequada somente a si mesmo" (ROUSSEAU, 1978, p. 68). Tal perspectiva, por exemplo, pode ser identificada nas correntes filosóficas contemporâneas do comunitarismo e do multiculturalismo.

Para Rousseau, o poder pertence ao povo e não pode pertencer senão a ele. Há, na política republicana, uma dependência do poder administrativo em relação ao comunicativo, decorrente do processo de formação da vontade e opinião pública. Ou

\footnotetext{
${ }^{3}$ Habermas, quando se refere ao republicanismo, fala acerca da tradição republicana vinda de Aristóteles e Rousseau. O republicanismo, porém, tal qual destaca Newton Bignotto, possui várias tradições, com suas respectivas diferenças, a saber: a matriz romana, italiana, inglesa, francesa e norte-americana. Ver em: BIGNOTTO, N (Org.). Matrizes do Republicanismo. Belo Horizonte: Editora UFMG, 2013, p.175229.
}

\begin{tabular}{|l|l|l|l|l|}
\hline Qovista Dialectus & Ano 4 & n. 11 & Agosto - Dezembro 2017 & p. $280-296$ \\
\hline
\end{tabular}


seja, o paradigma da política republicana não é o mercado, e sim a interlocução entre os cidadãos.

\begin{abstract}
No entendimento republicano, a formação política da opinião e da vontade, na esfera pública e no parlamento, não obedece às estruturas de processos do mercado, mas às estruturas próprias de uma comunicação pública orientada pelo entendimento. Para a política no sentido de uma prática de autodeterminação de cidadãos, o paradigma não é o mercado, mas o do diálogo (HABERMAS, 1997a, p.338) ${ }^{4}$.
\end{abstract}

Nada mais perigoso, diz Rousseau, que a influência dos interesses privados nos negócios públicos. Nesse sentido, há menos centralização do poder administrativo e estatal, em prol da capacidade comunicativa dos cidadãos. Este aspecto é o que Habermas considera positivo no modelo republicano, que o influenciará no conceito de democracia deliberativa.

Habermas argumenta que o modelo republicano de política tem a seu favor o fato de se firmar no sentido radicalmente democrático de uma auto-organização da sociedade pelos cidadãos, por via comunicativa, não remetendo os fins coletivos somente a uma negociação entre interesses particulares opostos. "Segue-se daí que o primeiro de todos os bens não é a autoridade, mas a liberdade" (ROUSSEAU, 2004, p.81). Em Rousseau, há uma radical crítica à representação, pois uma verdadeira democracia acontece apenas à medida que o povo participa diretamente das decisões.

A ideia de representantes, explica Rousseau, é moderna, vindo também do Governo feudal. Nas antigas repúblicas, diz ele, jamais o povo teve representantes, não se conhecendo tal palavra.

(...) falo somente das razões pelas quais os povos modernos, que se creem livres, têm representantes, e porque os povos antigos não os tinham. De qualquer modo, no momento em que um povo se dá representantes, não é mais livre; não mais existe (ROUSSEAU, 1978, p.100).

Portanto, em Rousseau, há a valorização da chamada liberdade dos antigos, ou seja, a liberdade da comunidade, pois o verdadeiro fundamento da sociedade faz-se por meio do povo. Rousseau fala acerca de um eu comum que caracteriza a vontade do

\footnotetext{
4 "Nach republikanischer Auffassung gehorcht die politische Meinungs - und Willensbildung in Öffentlichkeit und Parlament nicht den Strukturen von Marktprozessen, sondern den eigensinnigen Strukturen einer verständigungsorientierten öffentlichen Kommunikation. Für Politik im Sinne einer Praxis staatsbürgerlicher Selbstbestimmung ist das Paradigma nicht der Markt, sondern das Gespräch" (HABERMAS, 1992, p.331-332).

\begin{tabular}{|c|l|l|l|l|}
\hline Govista Dialectus & Ano 4 & n. 11 & Agosto - Dezembro 2017 & p. 280-296 \\
\hline
\end{tabular}
}


povo. Essa pessoa pública, que se forma pela união de todas as outras, explica ele, tomava antigamente o nome de cidade e, hoje, o de república ou de corpo político.

Para Habermas, entretanto, há, em Rousseau, uma sobrecarga ética do cidadão. Rousseau, de acordo com a leitura habermasiana, contou com virtudes políticas ancoradas no ethos de uma comunidade mais ou menos homogênea, integrada através de tradições culturais comuns, algo insustentável, hoje em dia, em sociedades plurais e complexas.

Segundo Habermas, o liberalismo e o republicanismo possuem respostas insuficientes para os desafios normativos de sociedades pluralistas, à medida que o liberalismo enfatiza apenas as liberdades individuais, e o republicanismo as da comunidade. Seria preciso, a um só instante, estabelecer um conceito de política que destacasse ambas as perspectivas.

No conceito republicano de soberania popular, perde-se o sentido universalista do princípio do direito. De acordo com Habermas, o republicanismo trabalharia com a ideia de uma nação etnicamente homogênea ou com a perspectiva de uma comunidade que tem o mesmo destino e segue as mesmas tradições, algo inviável, diz ele, para sociedades pluralistas, carentes de princípios normativos legitimados a partir das diversas visões de mundo.

Nesse sentido, tal qual demonstra Rúrion Melo, diferentemente de Marx, Habermas não utiliza o termo sociedade emancipada quando se refere à orientação crítico-emancipatória, mas sim formas de vida emancipadas. Pois, sociedades complexas e plurais, "inviabilizam a imagem de uma sociedade tomada em seu todo" (MELO, 2013, p.295), como no modelo republicano. Habermas vê como desvantagem o fato do republicanismo ser bastante idealista, tornando o processo democrático dependente das virtudes de cidadãos voltados ao bem comum.

\footnotetext{
Se a ideia de soberania popular ainda deve encontrar alguma aplicação realista nas sociedades altamente complexas, ela deve ser desvinculada da interpretação concretista que consiste em sua incorporação nos membros fisicamente presentes, participativos e co-determinantes de uma coletividade (HABERMAS, 2014, p.78-9).
}

Habermas também ressalta que, no republicanismo, o direito e a lei são instrumentos secundários em relação a uma comunidade que se autodetermina. A concepção republicana desprezaria a normatização jurídica, essencial no modelo habermasiano de democracia deliberativa, que veremos a seguir.

\begin{tabular}{|l|l|l|l|l|}
\hline Q Rovista Dialectus & Ano 4 & n. 11 & Agosto - Dezembro 2017 & p. $280-296$ \\
\hline
\end{tabular}




\section{O Conceito de Democracia Deliberativa}

Segundo Habermas, Rousseau e $\mathrm{Kant}^{5}$ tentaram articular a união prática e a vontade soberana no conceito de autonomia, de modo que a ideia dos direitos humanos e o princípio da soberania do povo se interpretassem mutuamente. Mesmo assim, para Habermas, eles não conseguiram entrelaçar simetricamente os dois conceitos. Kant, segundo Habermas, sugeriu um modo de ler a autonomia política que se aproxima mais da liberal, ao passo que Rousseau se aproximou mais do republicanismo.

Além disso, o liberalismo e o republicanismo ainda estariam presos a uma concepção de filosofia do sujeito e da consciência: o liberalismo centra-se no indivíduo e o republicanismo na comunidade ética. A democracia deliberativa habermasiana tenta acolher elementos de ambos os lados, integrando-os no contexto de um procedimento ideal para as tomadas de decisão.

Em consonância com o republicanismo, a democracia deliberativa de Habermas reserva uma posição central para o processo político de formação da opinião e da vontade, sem, no entanto, entender a constituição jurídico-estatal como algo secundário. A democracia deliberativa concebe os direitos fundamentais e os princípios do Estado de direito como uma resposta consequente à pergunta sobre como institucionalizar as exigentes condições de comunicação do procedimento democrático. Por um lado, o poder político depende do direito para se legitimar. Por outro, o direito necessita do aparato político estatal para ser posto.

A democracia deliberativa habermasiana, ao contrário do republicanismo, não torna a efetivação democrática dependente apenas de um conjunto de cidadãos coletivamente capazes de agir, e sim da institucionalização dos procedimentos que lhe digam respeito. Além disso, a democracia deliberativa, ao contrário também do modelo liberal, não opera com o conceito de um todo social centrado no Estado.

Entretanto, Habermas respeita a separação que há no modelo liberal entre Estado e sociedade, sem o centralismo político na figura do Estado. É importante enfatizar que, apesar de Habermas conservar certas características do liberalismo no seu

\footnotetext{
${ }^{5}$ Kant enfatiza que a dignidade da humanidade consiste precisamente na capacidade de ser legislador universal, com a condição de estar ao mesmo tempo submetido a essa mesma legislação. Ver em: KANT, I. Fundamentação da Metafísica dos Costumes. In: Os Pensadores. São Paulo: Abril Cultural, 1974, p.238.

\begin{tabular}{|c|l|l|l|l|}
\hline Govista Dialectus & Ano 4 & n. 11 & Agosto - Dezembro 2017 & p. 280-296 \\
\hline
\end{tabular}
}


conceito de democracia deliberativa, ele não pode ser considerado, como vários críticos ${ }^{6}$ às vezes o fazem, tal qual um pensador puramente liberal e normativista, no sentido pejorativo.

Habermas conserva os momentos positivos do liberalismo e do republicanismo, ao mesmo tempo em que supera aquilo que considera negativo tanto de um como de outro. É a partir da síntese do liberalismo e do republicanismo, rumo a uma democracia deliberativa, que o poder socialmente integrativo da solidariedade precisa, como diz Habermas, desdobrar-se sobre opiniões públicas autônomas e procedimentos institucionalizados por via jurídico-estatal, para a formação democrática da opinião e da vontade.

A democracia deliberativa trabalha com a imagem de uma sociedade descentralizada, pois o sistema político não é o topo nem o centro da sociedade, muito menos o modelo que determina sua marca estrutural, e sim um sistema de ação ao lado de outros.

Eu parto da ideia segundo a qual existe um entrelaçamento entre diferentes formas de comunicação, as quais têm que ser organizadas de modo que possamos supor que elas são capazes de ligar a administração pública a premissas racionais e de disciplinar o sistema econômico sob pontos de vista sociais e ecológicos, sem arranhar sua lógica própria. Este seria um modelo de democracia deliberativa (HABERMAS, 1997b, p.295) ${ }^{7}$.

Como ainda veremos, não há um privilégio da política a ser realizada somente na sociedade civil ou no parlamento. O conceito de democracia deliberativa abrange também uma exigente relação entre esfera pública e parlamento. Embora Habermas aborde o tema da esfera pública em uma obra de sua juventude (Mudança

\footnotetext{
${ }^{6}$ FARIAS, F. A Globalização e o estado cosmopolita: As antinomias de Jürgen Habermas. São Paulo: Cortez Editora, 2001. p.34: “[...] a revisão de Habermas não leva simplesmente a uma nova teoria crítica, cuja pertinência pode ser questionada a partir da ontologia do ser social. Conduz, também, ao abandono do marxismo em prol da apologia de um velho liberalismo". Já para Perry Anderson, por exemplo, a adesão de Habermas à democracia parlamentar é historicamente tão convencional para o seu tempo, como a de Hegel à monarquia constitucional. Ver em: ANDERSON, P. O Fim da história: de Hegel a Fukuyama. Rio de janeiro: Jorge Zahar Editores, 1992. p. 78-9.

7 "Ich gehe dabei von einer Vernetzung verschiedener Kommunikationsformen aus, die allerdings so organisiert sein müßten, daß sie die Vermutung für sich haben, die öffentliche Verwaltung an rationale Prämissen zu binden und auf diesem Wege auch das Wirtschaftssystem, ohne dessen eigene Logik anzutasten, unter sozialen und ökologischen Gesichtspunkten zu disziplinieren. Das ist ein Modell deliberativer Politik" (HABERMAS, 1992, p.649).
}

\begin{tabular}{|l|l|l|l|l|}
\hline Q Ronita Dialectus & Ano 4 & n. 11 & Agosto - Dezembro 2017 & p. $280-296$ \\
\hline
\end{tabular}


Estrutural da Esfera Pública ${ }^{8}$ ), nossa análise se concentrará, aqui, como anunciamos antes, em Direito e Democracia.

\section{A Esfera Pública em Direito e Democracia: o papel dos movimentos sociais.}

A discussão da esfera pública representou um elemento central no processo de reconstrução da Teoria Crítica na segunda metade do século XX, produzindo uma grande mudança nessa tradição teórica. Habermas passou a se preocupar cada vez mais com fundamentos normativos que permitissem estabelecer uma nova relação entre teoria crítica e teoria democrática.

Em Direito e Democracia, Habermas diz que a esfera pública é um "fenômeno social elementar". Ela é descrita como uma rede de comunicação de conteúdos, tomadas de posição e opiniões, em sintonia com a prática comunicativa cotidiana. Habermas argumenta que a sociedade civil contemporânea compõe-se de organizações e associações que captam os ecos dos problemas sociais ressonantes nas esferas privadas, transmitindo-os para o sistema político, bem como colocando as questões à luz da discussão pública.

A abordagem habermasiana a partir de Direito e Democracia nos permite distinguir uma dimensão de organização dos movimentos sociais, diferenciada do sistema político, mas que se relaciona ao mesmo tempo com ele.

Uma prática de autodeterminação deliberativa só pode desenvolver-se no jogo entre a formação da vontade de corporações parlamentares, programada para decisões e institucionalizada conforme o direito procedimental, e a formação política da opinião nos círculos informais da comunicação política (HABERMAS, 1997a, p.340) ${ }^{9}$.

Habermas, a partir de uma contextualização acerca da problemática da esfera pública na contemporaneidade, enfatiza que a sociedade civil pode, em "certas

\footnotetext{
${ }^{8}$ Em minha dissertação de mestrado, mostro especificamente a diferença e a mudança de análise da esfera pública entre as obras Mudança Estrutural da Esfera Pública e Direito e Democracia. Ver em: OLIVEIRA, J. Ação Comunicativa e Democracia: por uma democracia deliberativa em Jürgen Habermas. Disponível em:http://www.teses.ufc.br/tde_busca/processaPesquisa.php?listaDetalhes\%5B $\% 5 \mathrm{D}=2435 \&$ processar $=\mathrm{Pr}$ ocessar. Acesso em 16 nov. 2014.

9 "Eine deliberative Selbstbestimmungspraxis kann sich nur im Zusammenspiel der verfahrensrechtlich institutionalisierten, auf Entscheidungen programmierten Willensbildung parlamentarischer Körperschaften einerseits, mit der politischen Meinungsbildung in den informellen Kreisläufen der politischen Kommunikation andererseits entfalten" (HABERMAS, 1992, p.334).

\begin{tabular}{|c|l|l|l|l|}
\hline QRovista Dialectus & Ano 4 & n. 11 & Agosto-Dezembro 2017 & p. $280-296$ \\
\hline
\end{tabular}
}


circunstâncias", ter opiniões públicas próprias, capazes de influenciar e modificar o rumo do poder oficial. Para Habermas, movimentos sociais podem conduzir a atenção para determinados temas e dramatizar certos aportes numa esfera pública pluralista.

Para os movimentos sociais, diz Habermas, é questão de vida ou morte a possibilidade de encontrar formas solidárias de organização e esferas públicas que permitam esgotar e radicalizar direitos e estruturas comunicacionais existentes. Segundo ele, os atores da sociedade civil assumem um papel surpreendentemente ativo e pleno de consequências, quando tomam consciência de situações de crise.

Habermas defende que a sociedade civil, por meio das esferas públicas e das reivindicações trazidas pelos movimentos sociais, é capaz de introduzir no sistema político discussões sobre os problemas existentes na sociedade. A estrutura comunicacional da esfera pública possibilita que a sociedade civil reflita acerca dos problemas, conseguindo captá-los e identificá-los antes mesmo que o sistema político. Não é o aparelho do Estado nem as grandes organizações, argumenta Habermas, que geralmente questionam os problemas existentes na sociedade civil, e sim as iniciativas vindas das esferas públicas comunicacionais.

Em Habermas, mesmo que os partidos políticos passem a gravitar em torno do mercado, podem surgir movimentos contrários no interior da sociedade civil. É nesse sentido que ele enfatiza que a sociedade pode influir na transformação do sistema político constituído. Habermas destaca a existência de públicos não institucionalizados capazes de se organizar no âmbito da sociedade. Podemos dizer que, na teoria democrática habermasiana, há uma compatibilização entre esferas públicas e sistema político.

A esfera pública forma uma estrutura intermediária que faz a mediação entre o sistema político de um lado, e os setores privados do mundo da vida de outro. Habermas explica que, em sociedades complexas e pluralistas, aquilo que poderia ser uma esfera pública, como nos moldes de outrora, ramifica-se em diversos números de arenas internacionais, nacionais, regionais, comunais e subculturais, que se sobrepõem umas as outras. Estas redes se articulam objetivamente de acordo com pontos de vista funcionais, temas, círculos políticos etc. Assumem também a forma de esferas públicas "mais ou menos especializadas", porém, ainda acessíveis a um público de leigos. Por exemplo: esferas públicas literárias, eclesiásticas, artísticas, feministas, entre outras.

\begin{tabular}{|l|l|l|l|l|}
\hline Q Rovista Dialeatus & Ano 4 & n. 11 & Agosto - Dezembro 2017 & p. $280-296$ \\
\hline
\end{tabular}


Além disso, a esfera pública ramifica-se, na atualidade, em três outras modalidades, levando-se em consideração a densidade da comunicação, a complexidade organizacional e o alcance comunicacional. São elas: esfera pública episódica (bares, cafés, encontros na rua), esfera pública da presença organizada (encontros de pais, público que frequenta teatro, concertos de rock, reuniões de partidos ou congresso de igrejas) e esfera pública abstrata, produzida pela mídia (leitores, ouvintes e espectadores singulares, espalhados globalmente).

Apesar das diferenciações, as esferas, constituídas através da linguagem comum ordinária, são flexíveis, permitindo uma ligação entre elas próprias. Diante disso, Habermas justifica que limites sociais internos decompõem o "texto" da esfera pública, que se estende radicalmente em todas as direções, sendo transcrita de modo contínuo, em inúmeros pequenos "textos". Isto é, há uma fragmentação da esfera pública, haja vista o aumento da complexidade e da pluralidade da sociedade civil. Entrementes, para Habermas, o aumento da fragmentação na modernidade não nos obriga a abandonar projetos universalistas.

Há, segundo ele, inclusive, um crescimento da solidariedade entre cidadãos, para além das fronteiras dos estados nacionais. Há uma ampliação da esfera pública mundialmente, porque os cidadãos deliberam acerca de questões que atingem os homens como um todo (problemas econômicos, políticos, ecológicos, entre outros). Anthony Giddens, por exemplo, destaca que, na contemporaneidade, há vários movimentos sociais com suas respectivas reivindicações, naquilo que denomina de "caráter multidimensional da modernidade" (GIDDENS, 1991, p. 158).

Assim, as esferas públicas se reproduzem através do agir comunicativo, constituindo uma estrutura comunicacional, a qual tem a ver com o espaço social gerado na práxis comunicativa, por meio das argumentações e das problematizações dos atores. Habermas fala, inclusive, de uma esfera pública mundial, capaz de agir em torno de problemas globais, para além da lógica dos Estados nacionais, rumo a uma constelação pós-nacional. Ele explica que os movimentos sociais de atuação global são os principais motores da esfera pública supranacional.

As opiniões públicas, nacionais ou pós-nacionais, representam potenciais de influência política que podem ser utilizados para interferir na formação da vontade, nas corporações parlamentares, instituições no âmbito global, governos e tribunais. A esfera pública contemporânea pode ser entendida como um campo de tensão entre mundo da

\begin{tabular}{|l|l|l|l|l|}
\hline Q Ponista Dialectus & Ano 4 & n. 11 & Agosto - Dezembro 2017 & p. 280-296 \\
\hline
\end{tabular}


vida, de um lado, e sistemas político e jurídico, de outro, tanto no âmbito nacional como pós-nacional.

A democracia deliberativa, em Habermas, deve ser entendida a partir da relação entre o polo da administração e o da participação social: as decisões tomadas no sistema político precisam ser fundamentadas e justificadas na sociedade, através de uma esfera pública vitalizada. O sistema político deve estar ligado às redes periféricas da esfera pública política, por meio de um fluxo de comunicação que parta das redes informais da esfera pública, institucionalizando-se no parlamento.

\section{Conclusão}

Como destaca Seyla Benhabib (2007), as especificações do modelo deliberativo de política, privilegiam uma pluralidade de modos de associação na qual todos os atingidos podem articular seus pontos de vista. Tais modos de associação podem variar de partidos políticos, igrejas, iniciativas de cidadãos, movimentos sociais, associações voluntárias etc. Segundo Benhabib, a ideia de uma assembleia na qual o povo unido expressaria sua vontade pertence à história antiga da teoria democrática, como no republicanismo. O modelo deliberativo habermasiano, ao contrário, privilegia as esferas públicas fragmentadas que se articulam através de interesses comuns, com as instituições e o parlamento.

A sociedade, quando em crise, serve-se da opinião pública e dos movimentos sociais para atualizar os conteúdos normativos do Estado democrático de direito, protestando contra a inércia sistêmica da política institucional. O Estado democrático de direito não se apresenta como uma configuração pronta, e sim como um empreendimento arriscado, delicado, falível e carente sempre de revisão.

Habermas se opõe, portanto, à ideia de que o Estado administrativo e a esfera pública seriam necessariamente instâncias antagônicas e inconciliáveis democraticamente. Em realidade, ao introduzir os movimentos sociais na discussão acerca da política, Habermas abre espaço para a integração de novos atores, práticas e relações entre Estado e sociedade civil, seguindo a ideia da democracia deliberativa, por meio de uma síntese entre o liberalismo e o republicanismo.

\section{Referências Bibliográficas}

\begin{tabular}{|l|l|l|l|l|}
\hline Q Rovista Dialectus & Ano 4 & n. 11 & Agosto - Dezembro 2017 & p. $280-296$ \\
\hline
\end{tabular}


ANDERSON, P. O Fim da História: de Hegel a Fukuyama. Rio de janeiro: Jorge Zahar Editores, 1992.

ARISTÓTELES. A Política. 2.ed. Bauru: EDIPRO, 2009a.

Ética a Nicômaco. São Paulo: Editora Atlas, 2009b.

BENHABIB, S. Sobre um modelo deliberativo de legitimidade democrática. In: WERLE, D; MELO, R (orgs). Democracia Deliberativa. São Paulo: Editora Singular. 2007.

BIGNOTTO, N (Org). Matrizes do Republicanismo. Belo Horizonte: Editora UFMG, 2013.

HABERMAS, J. Faktizität und Geltung. Beiträge zur Diskurstheorie des Rechts und des demokratische Rechitstaats. Frankfurt am Main: Suhrkamp, 1992.

Direito e Democracia: Entre Facticidade e Validade (volume I). Rio de Janeiro: Tempo Brasileiro, 1997a.

. Direito e Democracia: Entre Facticidade e Validade (volume II). Rio de Janeiro: Tempo Brasileiro, 1997b.

- Prefácio à Nova Edição. In: Mudança Estrutural da Esfera Pública: investigações sobre uma categoria da sociedade burguesa. São Paulo: Unesp, 2014.

FARIAS, F. A Globalização e o Estado Cosmopolita: as antinomias de Jürgen Habermas. São Paulo: Cortez Editora, 2001.

GIDDENS, A. As Consequências da Modernidade. São Paulo: Editora Unesp, 1991.

KANT, I. Fundamentação da Metafísica dos Costumes. In: Os Pensadores. São Paulo: Abril Cultural, 1974.

LOCKE, J. Segundo Tratado Sobre o Governo. In: Os Pensadores. 2.ed. São Paulo: Abril Cultural, 1978.

MELO, R. Marx e Habermas: Teoria Crítica e os Sentidos da Emancipação. São Paulo: Editora Saraiva, 2013.

OLIVEIRA, J. Ação comunicativa e democracia: por uma política deliberativa em Jürgen Habermas. Disponível em: http://www.teses.ufc.br/tde_busca/processaPesquisa.php?listaDetalhes\%5B\%5D=2435 \&processar=Processar. Acesso em 16 nov. 2014.

REPA, L. Jürgen Habermas e o Modelo Reconstrutivo de Teoria Crítica. In: NOBRE, M. (Org.). Curso Livre de Teoria Crítica. Campinas: Papirus Editora, 2008.

ROUSSEAU, J. Do contrato social. 2.ed. São Paulo: Abril Cultural, 1978.

\begin{tabular}{|l|l|l|l|l|}
\hline Q Povista Dialeatus & Ano 4 & n. 11 & Agosto - Dezembro 2017 & p. $280-296$ \\
\hline
\end{tabular}


Emílio ou Da Educação. 3.ed. São Paulo: Martins Fontes, 2004.

SILVA, F. Democracia Deliberativa. In: NOBRE, M. (Org.). Curso Livre de Teoria Crítica. Campinas: Papirus Editora, 2008.

\begin{tabular}{|l|l|l|l|l|}
\hline Q Povista Dialeatus & Ano 4 & n. 11 & Agosto - Dezembro 2017 & p. $280-296$ \\
\hline
\end{tabular}

